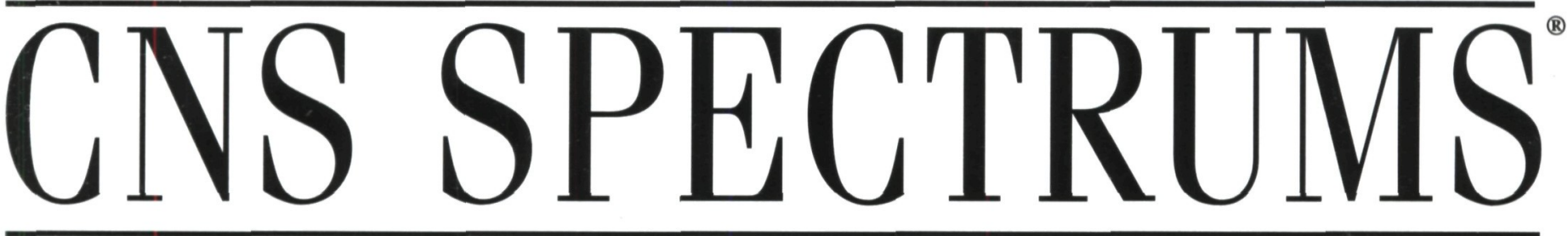

The International Journal of Neuropsychiatric Medicine

\title{
8
}

\section{Neuroscientific Approach to Emotions and Feelings: \\ The Last Frontier of the New Millennium}

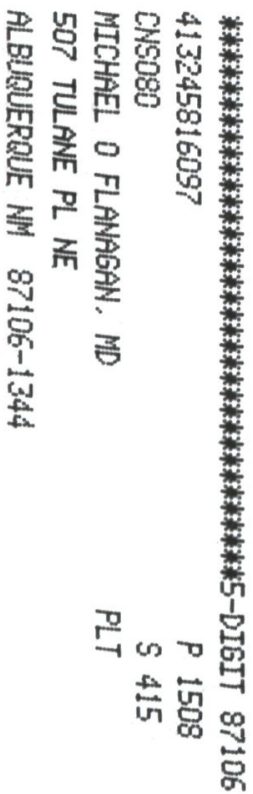

Emotions, Brain Development, and

Psychopathologic Vulnerability

S. Galderisi and A. Mucci

\section{Original Research \\ The Obsessive-Compulsive Spectrum: \\ A Survey of $\mathbf{8 0 0}$ Practitioners \\ E. Hollander, R. Twersky, and C. Bienstock}




\section{In mild to moderate Alzheimer's disease}

\section{You see it as maintaining cognitive}

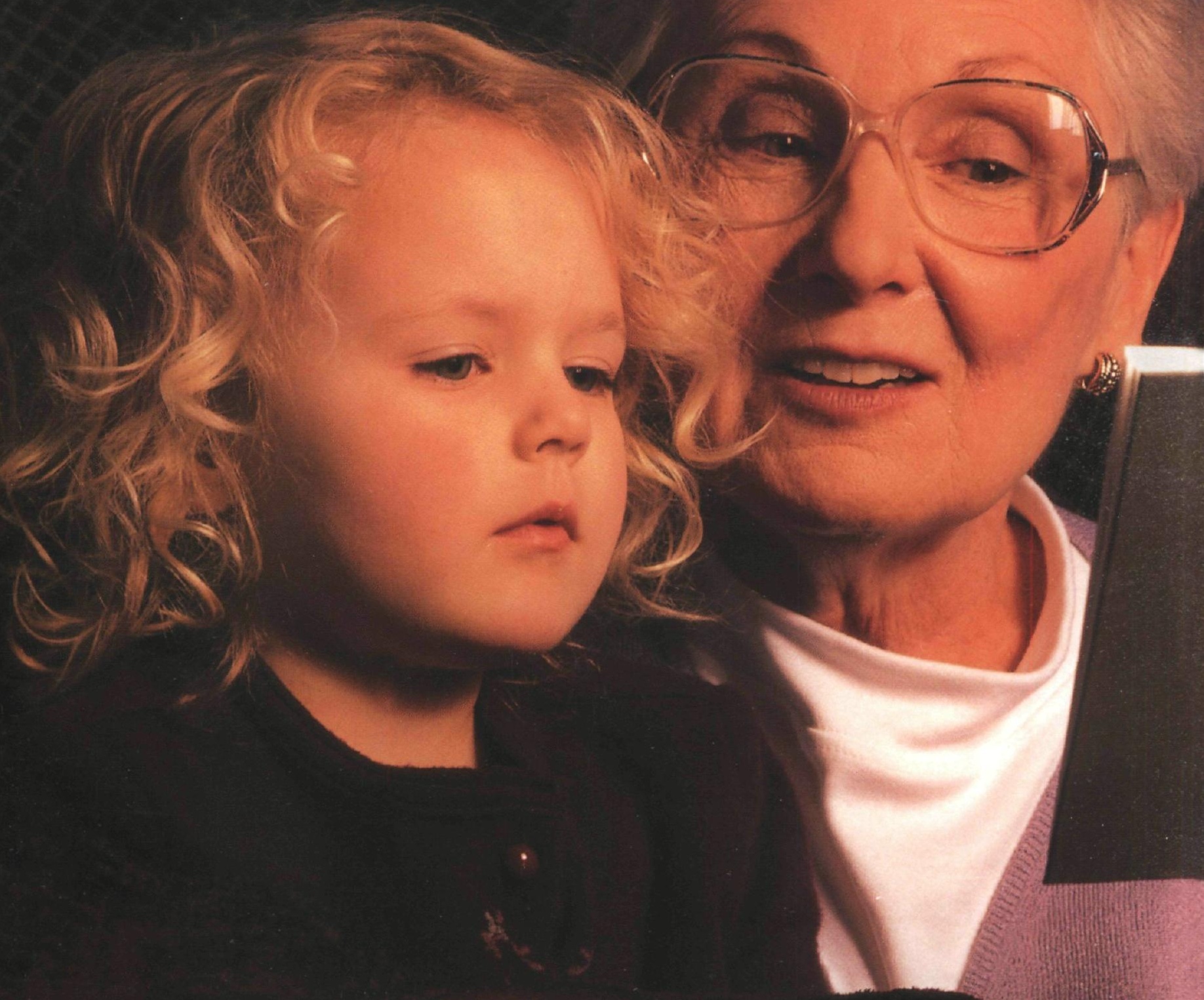

* Individual responses to ARICEPT ${ }^{\oplus}$ may include improvement, stabilization, or decline.

† The most common adverse events in pivotal clinical trials with ARICEPT ${ }^{\oplus}$ were nausea, diarrhea, insomnia, vomiting, muscle cramps, fatigue, and anorexia. Pivotal clinical trials of ARICEPT ${ }^{\oplus a v e ~ s h o w n ~ n o ~ i n c r e a s e, ~ r e l a t i v e ~ t o ~ p l a c e b o, ~ i n ~ t h e ~ i n c i d e n c e ~ o f ~ e i t h e r ~}$ peptic ulcer disease or gastrointestinal bleeding. Nevertheless, cholinesterase inhibitors may be expected to increase gastric acid secretion. Therefore, patients (especially those at increased risk for developing ulcers - eg, having a history of ulcer disease, receiving concurrent nonsteroidal anti-inflammatory drugs) should be monitored closely for gastrointestinal bleeding. In pivotal clinical trials, syncopal episodes have been reported in association with ARICEPT $^{\oplus}$ ( $2 \%$ vs $1 \%$ for placebo). 


\section{function.}

She sees it as

a bedtime story.

ARICEPT $^{\oplus}$. Helping to make

a difference for people living with Alzheimer's

- Slows the worsening of symptoms*

- Proven to maintain cognition in placebo-controlled studies

- Well tolerated ${ }^{\dagger}$

- Proven safety profile

- Once-daily dosing

- 3 years of real-world use

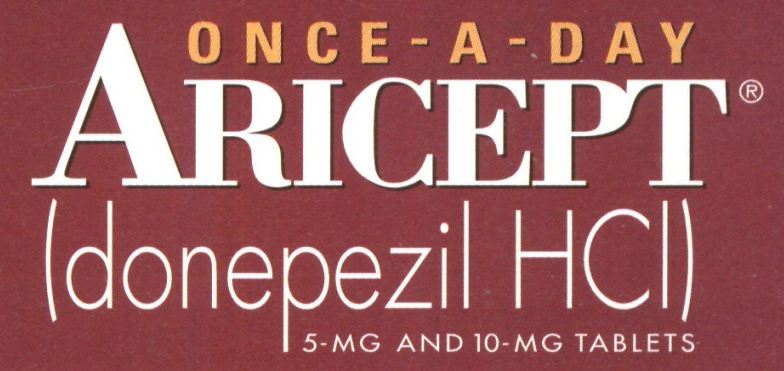

Therapy TO REMEMBER

Please see brief summary of prescribing information on adjacent page. 
ARICEPT• (Donepezll Hydrochlorlde Tablets)

Brief Sumnary - see package insert for full prescribing information. INDICATIONS AMD USAGE ARICEPT is indicated for the rreatment of mild to moderate dementia of the Alzheimer's type. CONTRAINDICATIONS ARICEPT is contraindicated in patients with known hypersensitivity to donepezil hydrochloride or to piperidine derivatives. WARNINGS Anesthesia: ARICEPT as a cholinesterase inhibitor, is likely to exagoerate succinylcholine-type muscle relaxation during anesthesia. Cardlovaseular Condtlions: Because of their pharmacological action, cholinesterase inhibitors may have vacotonic effects on hear rate (e g. bradycardia). The potential for this action may be particularly important to patients with "sick sinus syndrome" or other supraventricular cardiac conduction conditions. Syncopal episodes have been reported in association with the use of ARICEPT. Gastrolmtestinal Conditions: Through their primary action, cholinesterase inhibitors may be expected to increase gastric acid secretion due to increased cholinergic activity. Therefore, patients should be monitored closely for symptoms of active or occult gastrointestinal bleeding, especially those at increased risk for developing uicers, e.g. those with a history of ulcer disease or those receiving concurrent nonsteroidal anti-inflammatory drugs (NSAIDS). Clinical studies of ARICEPT have shown no increase, relative to placebo, in the incidence of either peptic ulcer disease or gastrointestinal bleeding. ARICEPT as a predictable consequence of its pharmacological properties, has been shown to produce diarrhea, nausea and vomiting. These effects, when they occur, appear more trequently with the $10 \mathrm{mg} / \mathrm{day}$ dose than with the $5 \mathrm{mg} /$ day dose. In most cases, these effects have been mild and transient, sometimes lasting one to three weeks, and have resolved during continued use of ARICEPT. Genllourinary: Although not observed in clinical trials of ARICEPT ${ }^{*}$, cholinomimetics may cause bladder outflow obstruction. Nouroleales/ Condtlons: Seizures: Cholinomimetics are believed to have some potential to cause generalized convulsions. However, seizure activity also may be a manifestation of Alzheimer's Disease. Pulmonsry Conditions: Because of their cholinomimetic actions, cholinesterase inhibitors should be prescribed with care to patients with a history of asthma or obstructive pulmonary disease. PRECAUTIONS Drug-Drug Interactions Drugs Highly Bound to Plasma Proloins: Drug displacement studies have been perlormed in vitro between this highly bound drug (96\%) and other orugs such as furosemide, digoxin, and warfarin. ARICEPT at concentrations of $0.3-10 \mu \mathrm{g} / \mathrm{mL}$ did not affect the binding of furosemide $(5 \mu \mathrm{g} / \mathrm{mL})$, digoxin $(2 \mathrm{ng} / \mathrm{mL})$, and warfarin $(3 \mu \mathrm{g} / \mathrm{mL})$ to human albumin. Similarly, the binding of ARICEPT to human albumin was not aftected by furosemide, digoxin, and warfarin. Effect of ARICEPP on the Motabollsm of Other Dnugs: No in vivo clinical trials have investigated the effect of ARICEPT ${ }^{\oplus}$ on the clearance of drugs metabolized by CYP $3 A 4$ (e.g. cisapride, terfenadine) or by CYP $2 D 6$ (e.g. imipramine). However, in vitro studies show a low rate of binding to these enzymes (mean $K_{i}$ about $50-130 \mu \mathrm{M}$ ), that, given the therapeutic plasma concentrations of donepezil $(164 \cap M)$, indicates little likelihood of interierence. Whether ARICEPT ' has any potential for enzyme induction is not known. Ettoct of Other Drugs on the Metabollsm of ABICEPT. Ketoconazole and quinidine inhibitors of CYP450,3A4 and 2D6, respectively, inhibit donepezil metabol ism in vitro. Whether there is a clinical effect of these inhibitors is not known. Inducers of CYP $2 D 6$ and CYP $3 A 4$ (e.g., phenytoin, carbamazepine, dexamethasone, rifampin, and phenobarbital) could increase the rate of elimination of ARICEPT. Use with Anticholinergics: Because of their mechanism of action, cholinesterase inhibitors have the potential to interfere with the activity of anticholinergic medications. Use with Chollnomimolles and Other Chollnestorase Inhlbltors: A synergistic effect may be expected when cholinesterase inhibltors are given concurrently with succinylcholine, similar neuromuscular blocking agents or cholinergic agonists such as bethanechol. Carcinogenesis, Mutagenesis, Impairment of Fertllity Carcinogenicity studies of donepezil have not been completed. Donepezil was not mutagenic in the Ames reverse mutation assay in bacteria. In the chromosome aberration test in cultures of Chinese clastogenic in the in vivo mouse micronucleus test. Donepezil had no effect on fertility in rats at doses up to $10 \mathrm{mg} / \mathrm{kg} / \mathrm{day}$ (approximately 8 times the maximum recommended human dose on a mg/m² basis). Pregnaney Prognancy Calogory C: Teratology studies conducted in pregnant rats at doses up to $16 \mathrm{mg} / \mathrm{kg} /$ day (approximately 13 times the maximum recommended human dose on a $\mathrm{mg} / \mathrm{m}^{2}$ basis) and in pregnant rabbits at doses up to $10 \mathrm{mg} / \mathrm{kg} / \mathrm{day}$ (approximately 16 times the maximum recommended human dose on a $\mathrm{mg} / \mathrm{m}^{2}$ basis) did not disclose any evidence for a teratogenic potential of donepezil. However, in a study in which pregnant rats were given up $1010 \mathrm{mg} / \mathrm{kg} / \mathrm{day}$ (approximately 8 times the maximum recommended human dose on a $\mathrm{mg} / \mathrm{m}^{2}$ basis) from day 17 of gestation through day 20 postpartum, there was a slight increase in still biths and a slight decrease in pup survival through day 4 postpartum at this dose; the next lower dose tested was $3 \mathrm{mg} / \mathrm{kg} /$ day. There are no adequate or well-controlled

the next lower dose tested was $3 \mathrm{mg} / \mathrm{kg} / \mathrm{day}$. There are no adequate or well-controlled risk to the fetus. Mursing Mothers it is not known whether donepezil is excreted in human breast milk. ARICEPT ${ }^{\infty}$ has no indication for use in nursing mothers. Podiatric Use There are no adequate and well-controlled trials to document the safety and efficacy of ARICEPT in any iliness occurring in children. ADVERSE REACTIONS Adverse Events Leading to Dlecontinuation The rates of discontinuation from controlled clinical trials of ARICEPT ${ }^{*}$ due to adverse events for the ARICEPT $5 \mathrm{mg} / \mathrm{day}$ treatment groups were comparable to those of placebo-trealment groups at approximately $5 \%$. The rate of discontinuation of patients who received 7-day escalations from $5 \mathrm{mg} /$ day to $10 \mathrm{mg} /$ day, was higher at $13 \%$. The most common adverse events leading to discontinuation, defined as those occurring in at least $2 \%$ of patients and at twice the incidence seen in placebo patients, are shown in Table 1.

\section{Tabie 1. Most Frequent Adverse Events Leading to Withdrawal} from Controlled Clinical Trials by Dosa Group

\begin{tabular}{|c|c|c|c|}
\hline $\begin{array}{l}\text { Dose Group } \\
\text { Pationts Randomized } \\
\text { Event/\%Dlscontinulng }\end{array}$ & $\begin{array}{l}\text { Placebo } \\
355\end{array}$ & $\underset{350}{5 \mathbf{m g} / \text { day ARICEPT }}$ & $\begin{array}{c}10 \mathrm{mg} / \mathrm{day} \text { ARICEPT } \\
315\end{array}$ \\
\hline $\begin{array}{l}\text { Nausea } \\
\text { Diarntea } \\
\text { Vomiting }\end{array}$ & $\begin{array}{l}1 \% \\
0 \% \\
<1 \%\end{array}$ & $\begin{array}{l}1 \% \\
<1 \% \\
<1 \%\end{array}$ & $\begin{array}{l}3 \% \\
3 \% \\
2 \%\end{array}$ \\
\hline
\end{tabular}

Most Frequent Adverse Clinical Events Seen in Association with the Use of ARICEPT The most common adverse events, defined as those occurring at a frequency of at least $5 \%$ in patients receiving $10 \mathrm{mg} /$ day and twice the placebo rate, are largely predicted by ARICEPT 's cholinomimetic effects. These include nausea, diarricea, insomnia, vomiting. muscle cramp, fatigue and anorexia. These adverse events were often of mild intensity and transient, resolving during continued ARICEPT' treatment without the need for dose modification. There is evidence to suggest that the frequency of these common adverse events may be affected by the rate of titration. An open-label study was conducted with 269 patients who received placebo in the 15 - and 30-week studies. These patients were titrated to a dose of $10 \mathrm{mg} /$ day over a 6 -week period. The rates of common adverse events were lower than those seen in patients titrated to $10 \mathrm{mg} /$ day over one week in the controlled clinical trials and were comparable to those seen in patients on $5 \mathrm{mg} / \mathrm{day}$. See Table 2 for a comparison of the most common adverse events following one and six week titration regimens.

Table 2. Comparison of Rates of Adverse Events in Patients Titrated to $10 \mathrm{mg} /$ day Over 1 and 6 Weeks

\begin{tabular}{|c|c|c|c|c|}
\hline Adverse Event & $\begin{array}{l}\text { Placebo } \\
(n=315)\end{array}$ & $\begin{array}{c}\text { No titration } \\
5 \text { mg/day } \\
(n=311)\end{array}$ & $\begin{array}{c}\text { One-week titration } \\
10 \mathrm{mg} / \mathrm{day} \\
(\mathrm{n}=315)\end{array}$ & $\begin{array}{c}\text { Six-week titratlon } \\
10 \mathrm{mg} / \mathrm{day} \\
(\mathrm{n}=269)\end{array}$ \\
\hline Nausea & $6 \%$ & $5 \%$ & $19 \%$ & $6 \%$ \\
\hline Diarrhea & $5 \%$ & $8 \%$ & $15 \%$ & $9 \%$ \\
\hline Insomnia & $6 \%$ & $6 \%$ & $14 \%$ & $6 \%$ \\
\hline Fatigue & $3 \%$ & $4 \%$ & $8 \%$ & $3 \%$ \\
\hline Vomiting & $3 \%$ & $3 \%$ & $8 \%$ & $5 \%$ \\
\hline Muscle cramps & $2 \%$ & $6 \%$ & $8 \%$ & $3 \%$ \\
\hline Anorexia & $2 \%$ & $3 \%$ & $7 \%$ & $3 \%$ \\
\hline
\end{tabular}

Atwerse Events Reported in Controlied Trials The events cited reflect experience gained under closely monitored conditions of clinical trials in a highly selected patient population. In actual clinical practice or in other clinical trials, these frequency estimates may not apply, as the conditions of use, reporting behavior, and the kinds of patients treated may differ. Table 3 lists treatment emergent signs and symptoms that were reported in at least $2 \%$ of patients in placebo-conplacebo assigned patients. In general, adverse events occurred more frequently in female patients and with advancing age.

Table 3. Adverse Events Reported in Controlled Clinical Trials

in at Least $2 \%$ of Patients Recelving ARICEPT' (donepezil HCI) and at a Higher Frequency than Placeho-treated Pallents

\begin{tabular}{|c|c|c|}
\hline Body System/Adverse Event & $\begin{array}{l}\text { Placebo } \\
(n=355)\end{array}$ & $\begin{array}{r}\text { ARICEP } \\
\{n=747\end{array}$ \\
\hline \multicolumn{2}{|l|}{ Body as a Whole } & 74 \\
\hline Headache & 9 & 10 \\
\hline Pain, various locations & 8 & 9 \\
\hline Accident & 6 & 7 \\
\hline Fatigue & 3 & 5 \\
\hline \multicolumn{3}{|l|}{ Cardiovascular System } \\
\hline \multirow{2}{*}{\multicolumn{3}{|c|}{ Digestive System }} \\
\hline & & \\
\hline Nausea & 6 & 11 \\
\hline Diarrhea & 5 & 10 \\
\hline Vomiting & 3 & 5 \\
\hline Anorexia & 2 & 4 \\
\hline \multicolumn{3}{|l|}{ Hemic and Lymphatic System } \\
\hline Ecchymosis & 3 & 4 \\
\hline \multicolumn{3}{|l|}{ Metabolic and Nutritional Systems } \\
\hline Weight Decrease & 1 & 3 \\
\hline \multicolumn{3}{|l|}{ Musculoskeletal System } \\
\hline Muscle Cramps & 2 & 6 \\
\hline Arthritis & 1 & 2 \\
\hline \multicolumn{3}{|l|}{ Nervous System } \\
\hline Insomnia & 6 & 9 \\
\hline Dizziness & 6 & 8 \\
\hline Depression & $<1$ & 3 \\
\hline Abnormal Dreams & 0 & 3 \\
\hline Somnolence & $<1$ & 2 \\
\hline \multicolumn{3}{|l|}{ Urogenlial System } \\
\hline Frequent Urination & 1 & 2 \\
\hline
\end{tabular}

Other Adverse Events Observed During Clinical Trials ARICEPT has been administered to over 1700 individuals during clinical trials worldwide. Approximately 1200 of these patients have been treated for at least 3 months and more than 1000 patients have been treated for at least 6 months. Controlled and uncontrolled trials in the United States included approximately 900 patients. In regards to the highest dose of $10 \mathrm{mg} /$ day, this population includes 650 patients treated for 3 months, 475 patients treated for 6 months and 116 patients treated for over 1 year. The range of patient exposure is from 1

- DAY SPT

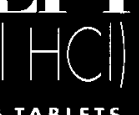

TABLETS to 1214 days. Treatment emergent signs and symptoms that occurred during
3 controlled clinical trials and two open-label trials in the United States were recorded a adverse events by the clinical investigators using terminology of their own choosing. provide an overall estimate of the proportion of individuals having similar trpes of events the events were grouped into a smaller number of standardized categories using a modified COSTART dictionary and event frequencies were calculated across all studies. These
Conter COSTART dictionary and event frequencies were calculated across all studies. These
categories are used in the listing below. The frequencies represent the proportion of categories are used in the listing below. The trequencies represent the proportion of
900 patients from these trials who experienced that event while receiving ARICEPT adverse events occurring at least twice are included, except for those already listed in Tables 2 or 3 , COSTART terms too general to be informative, or events less likely to be drug caused. Events are classified by body system and listed using the following definitions: frequent adverse events - those occurring in at least $1 / 100$ patients; infrequent adverse events - those occurring in $1 / 100$ to $1 / 1000$ patients. These adverse events are not necessarily related to ARICEPT' treatment and in most cases were observed at a similar frequency in placebo-treated patients in the controlled studies. No important additional adverse events were seen in studies conducted outside the United States. Body as a Whole: Frequent: influenza, chest pain, toothache; Infrequent: tever edema face, periorbital edema, hernia hiatal, abscess, cellulitis, chills, generalized coldness, head fullness, listlessness. Cardiovascular System: Frequent: hypertension, vasodiation, atrial fibrillation, hot flashes, hypotension; Infrequent angina pectoris, postural hypotension, myocardial infarction, AV block (first degree) congestive heart failure, arteritis, bradycardia, peripheral vascular disease, supraventricular, bradycardia, peripheral vascular disease, supraventricular tachycardia, deep vein thrombosis. Digestlve Systom: Frequent: fecal incontinence, gastrointestinal bleeding, bloating, epigastric, pain; Anfequent eructation, gingivitis, increased
appetite, flatulence, periodontal abscess, cholelithiasis, diverticulitis, drooling, ory mouth, tever sore, gastritis, irritable colon, tongue edema, epigastric distress, gastroenteritis, increased transaminases, hemorhoids, ileus, increased thirst, jaundice, melena, polydipsia, duodenal ulcer, stomach uilcer. Endocrine System: Infrequent diabetes mellitus, goiter Hemic and Lymphatic Syctom: Infrequent: anemia, thrombocythemia, thrombocytopenia, eosinophilia, enythrocytopenia. Metabolic and Wutthional Disonders: Frequent dehydration; Infequent gout, hypokalemia, increased creatine kinase, hyperglycernia, weight increase, increased lactate dehydrogenase. Musculoskoletal Systom: Frequent: bone fracture; Infrequent: muscle weakness, muscle fasciculation. Norveus system: Frequent: delusions, tremor, irritability, paresthesia, aggression, vertigo, ataxia, increased libido, restlessness, abnormal crying, nervousness, aphasia; infrequent: cerebrovascular accident, intracranial hemorrhage, transient ischemic attack, emotional lability, neuraigia, coldness (localized) accident, intracranial hemorrhage, transient ischennic attack, emotional lability, neuraigra, coldness (localized), muscie spasm, dysphoria, gait abnormality, hypentonia, hypokinesia, neurodermattitis, numbress (localized), paranoia, dysarthria, dysphasia, hostility, decreased libido, melanchoila, emotional withdrawal, nystagmus, pacing. Respiralory
system: Frequent: dyspnea, sore throat, bronchitis; infrequent: epistaxis, post nasal drip, pneumonia, hyperventilation pulmonary congestion, wheezing, hypoxia, pharyngitis, pleurisy, pulmonary collapse, sleep apnea, snoring. Skin ant Appendapes: Frequent: pruritus, diaphoresis, urticaria; Infrequent: dermatitis, erythema, skin discoloration, hyperkeratosis, alopecia, tungal demalitis, herpes zoster, hirsutism, skin strize, night sweats, skin ulcer. Special Senses: Frequent: cataract, eye irritation, vision blurred; intrequent: dry eyes, glaucoma, earache, tinnitus, blepharitis, decreased hearing, retinal hemorrhage, otitis externa, otitis media, bad taste, conjunctival hemorrhage, ear buzzing, motion sickness, spots before eyes. Urogenltal System: Frequent: urinary incontinence, nocturia: Infrequent: dysuria, hematuria, urinary urgency, metrorrhagia, cystitis, enuresis, prostate hypertrophy, pyelonephritis, inability to empty bladder, breast fibroadenosis, fibrocystic breast, mastitis, pyuria, renal failure, vaginitis. Postintroduction Reports voluntary reports of adverse events temporally associated with ARICEPT that have been received since market introduction that are not listed above, and that there is inadequate data to determine the causal relationship with the drug include the following: abdominal pain, agitation, there is inadequate data to determine the causal relationship with the drug include the following: abdominal pain, agitation,
cholecystits, confusion, convulsions, hallucinations, heart block (all types), hemolytic anemia, hepatitis, hyponatremia, cholecystitis, confusion, convulsions, hallucinations, heant block (all types), hemolylc anemia, hepaltits, hyponatremia, evolving, it is advisable to contact a Polson Control Conter to determine the latest recommendations for the management of an overdose of any drug. As in any case of overdose, general supportive measures should be utilized. Overdosage with cholinesterase inhibitors can result in cholinergic crisis characterized by severe nausea, vomiting salivation, sweating, bradycardia, hypotension, respiratory depression, collapse and convulsions. Increasing muscle weakness is a possibility and may result in death if respiratory muscles are involved. Tertiary anticholinergics such as atropine may be used as an antidote for ARICEPT* overdosage. Intravenous atropine sulfate tifrated to effect is recommended: an initial dose of 1.0 to $2.0 \mathrm{mg}$ IV with subsequent doses based upon clinical response. Atypical responses in blood pressure and heart rate have been reported with other cholinomimetics when co-administered with quaternary anticholinergics such as glycopyrrolate. It is not known whether ARICEPT* and/or its metabolites can be removed by dialysis (hemodialysis, peritoneal dialysis, or hemofiltration). Dose-related signs of toxicity in animals included reduced spontaneous movement, prone posidialysis, or hemonofitration). Dose-related signs of toxicity in animals included reduced spontaneous movernent, prone position, staggering gait, lacrimation, clonic convulsions, depressed respiration, salivation, miosis, tremors, fasciculation and
lower body surface temperature. DOSAGE AND ADMINISTRATION The dosages of ARICEPT shown to be effective in controlled clinical trials are $5 \mathrm{mg}$ and $10 \mathrm{mg}$ administered once per day. Controlled clinical trials indicated that the $10 \mathrm{mg}$ dose, with a one week titration, is likely to be associated with a higher incidence of cholinergic adverse events than the $\mathrm{mg}$ dose. Because steady state is not achieved for 15 days and because the incidence of such effects may be influenced by the rate of dose escalation, treatment with a dose of $10 \mathrm{mg}$ should not be contemplated until patients have been on a daily dose of $5 \mathrm{mg}$ for 4 to 6 weeks. Whether or not to employ a dose of $10 \mathrm{mg}$ is a matter of prescriber and patient preference. ARICEPT should be taken in the evening, just prior to retiring, and may be taken with or without food.

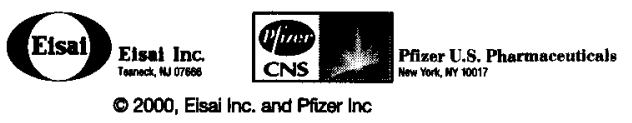




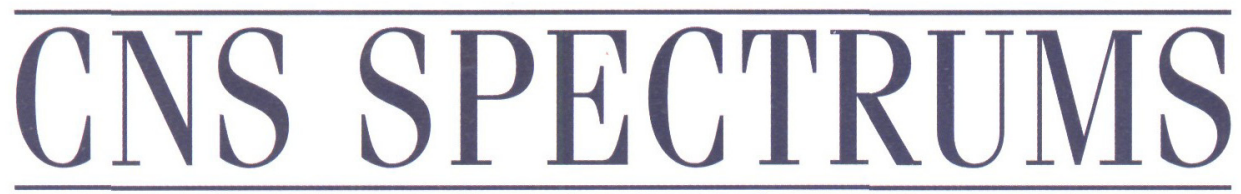

The International Journal of Neuropsychiatric Medicine

EDITOR

Eric Hollander, MD

Mount Sinai School of Medicine New York, NY

\section{INTERNATIONAL EDITOR}

Joseph Zohar, MD

Chaim Sheba Medical Center

Tel Aviv, Israel

\section{ASSOCIATE INTERNATIONAL EDITOR}

Donatella Marazziti, MD

University of Pisa

Pisa, Italy

\section{EDITORIAL DIRECTOR}

James La Rossa Jr.

\section{BOARD OF ADVISORS}

Margaret Altemus, MD

Cornell University Medical Center

New York, NY

Mitchell F. Brin, MD

Mount Sinai School of Medicine

New York, NY

John Caronna, MD

New York Hospital-Cornell

Medical Center, New York, NY

Dennis S. Charney, MD

Yale University

New Haven, CT

Emil F. Coccaro, MD

University of Chicago Medical Center

Chicago, IL

Jeffrey L. Cummings, MD

University of California

Los Angeles, CA
Dwight L. Evans, MD

University of Pennsylvania

Philadelphia, PA

Mark George, MD

Medical University of South Carolina Charleston, SC

Jack Gorman, MD

College of Physicians and

Surgeons, Columbia University

New York, NY

Thomas R. Insel, MD

Yerkes Primate Labs

Emory University School of Medicine Atlanta, GA

Lorrin M. Koran, MD

Stanford University Medical School

Stanford, CA

Herbert Y. Meltzer, MD

Vanderbilt University Medical Center Nashville, TN

Stuart A. Montgomery, MD

St. Mary's Hospital Medical School

London, United Kingdom

Dennis L. Murphy, MD

National Institute of Mental Health

Bethesda, MD

Charles B. Nemeroff, MD, PhD

Emory University School of Medicine Atlanta, GA

Humberto Nicolini, MD, PhD

Instituto Mexicano de Psiquiatria

Mexico

Katharine Phillips, MD

Brown University

Providence, RI
Harold A. Pincus, MD

American Psychiatric Association

Washington, DC

Stanley I. Rapoport, MD

National Institute of Mental Health Bethesda, MD

Scott L. Rauch, MD

Massachusetts General Hospital

Charlestown, MA

Alan Schatzberg, MD

Stanford University Medical School

Stanford, CA

Dan J. Stein, MB

University of Stellenbosch

Tygerberg, South Africa

Norman Sussman, MD

New York University Medical School New York, NY

Neal R. Swerdlow, MD, PhD

University of California, San Diego La Jolla, CA

Michael R. Trimble, MD

National Hospital for Neurology

and Neurosurgery

London, United Kingdom

H. M. van Praag, MD

University of Maastricht

Maastricht, The Netherlands

Herman G.M. Westenberg, MD

University Hospital Utrecht

Utrecht, The Netherlands

Richard Wyatt, MD

National Institute of Mental Health Bethesda, MD

Stuart Yudofsky, MD

Baylor College of Medicine

Houston, TX

\section{MBL COMMUNICATIONS}

CEO \& PUBLISHER

James La Rossa Jr.

PRESIDENT \&

ASSOCIATE PUBLISHER

Darren L. Brodeur

MANAGING EDITOR

Claire R. Roberts

\section{ASSOCIATE EDITORIAL DIRECTOR/ ACQUISITIONS EDITOR}

Genevieve Romano

SPECIAL PROJECTS EDITOR

Imre Balanli

SENIOR EDITORS

Jenny R. Green

Julie H. Kaufman

\section{ASSISTANT EDITORIAL DIRECTOR}

Kathleen Byrne

\section{ASSOCIATE EDITOR}

Keith Papa

EDITORIAL ASSISTANTS

Janeen Labbe

Amanda Schoenberg

Craig McRea Seip

Joshua Ubaldi

Jessica Wapner

ASSISTANT

ACQUISITIONS EDITOR

Dena Panteleakis

PUBLISHING ASSOCIATE

Jesse D. Soll

NATIONAL ACCOUNTS

MANAGER-

EMERGING MARKETS

Paul McDaniel
ART DIRECTOR

Anthony J. Korsak

\section{ASSISTANT ART DIRECTOR}

Benjamin Balcomb

COPY EDITORS

Lauren Cerruto

Michelle Cervone, MD

John Martino

\section{ADMINISTRATIVE ASSISTANT}

Claudette Crawford

CORPORATION COUNSEL

Kevin F. Saer, Esq.

Davis, Wright, \& Tremaine, LLP

\section{OF COUNSEL}

Susan G. La Rossa, Esq.

Putney, Twombly, Hali \& Hirson 


\section{DISROBING LIBIDO}

\section{page 21}

"After this organizational and inductive role of androgens at puberty, their influence on sexual activity decreases with age. Sexuality becomes more mature, intellectual, more mind-induced, and less hormonally driven. Nevertheless, some aspects of sexuality remain linked to hormones. A reduction of central arousability-the neurophysiologic substrate of sexual desire and spontaneous nocturnal erections-is typical of the hypogonadal state. Davidson et al have clearly shown that libido, the number of coital attempts, and spontaneous erections are strictly correlated to the dose of androgens administered in hypogonadal men. Ansong and Punwaney showed that in men with erectile dysfunction, sexual drive was partially related to levels of circulating testosterone. It is still not clear, however, at what level of androgen deficiency the loss of libido begins. Clinical experience and the available scientific experience suggest that a personal susceptibility exists and that, in some cases, other central inducers can overcome the role of androgens. Even in ancient times, some castrated men were said to have sexual activity. Moreover, patients with a history of prostate carcinoma who take drugs, such as gonadotropin-releasing hormone analogues, that lower plasma testosterone to undetectable levels still show sexual interest even in the absence of erectile function. Among other androgens, dehydroepiandrosterone (DHEA) has recently attracted the attention of scientists and even mass media. A recent double-blind pilot study on men infected with the human immunodeficiency virus showed that DHEA treatment had a positive effect on libido, mood, and body mass, regardless of baseline serum DHEA level."

\section{THE COMPLEXITY OF BOREDOM}

\section{page 24}

"The study of the pharmacology of opiates has led to stimulating findings on the biology of boredom. These substances exert a reward effect through the stimulation of dopaminergic neurons of the ventral tegmental area (mainly the $\mathrm{Al0}$ group) mediated by $\mu$ and $\Delta$ receptors. Several studies have reported relationships between opiate dependence and chronic feelings of boredom. According to Zuckerman's model, low levels of endogenous opiates in high sensation seekers may explain why they are more prone to heroin and cocaine use, as demonstrated by negative correlations between boredom susceptibility subscale scores and endorphin levels. The negative correlations among endorphin levels, sensation seeking, and average evoked potential augmentation and the positive correlations between endorphin levels and average evoked potential reduction strengthen the hypothesis that endogenous opiates may have a protective effect against an excessive stimulation, causing a behavioral depression. Average evoked potential reduction is, in fact, involved in the defensive function from overstimulation. According to Sicuteri, the endogenous opiates also may work as a euphoriant mechanism activated by emotional factors and exciting external situations (eg, job, sex, sports, etc). When the subject gives up the pleasant activity, boredom may appear with its related phenomena, such as yawns, restlessness, autonomic disturbances, and headache-a state that resembles a mild opiate withdrawal syndrome."

\section{THE PSYCHOLOGY OF SHAME page 28}

"The early recognition of innate factors gives rise to the hypothesis of the existence of some kind of innate central hardware involved in shame. Malin has hypothesized that a hard-wired pathway exists for nine basic affects: 'The positive affects of interest-excitement and enjoyment-joy, the neutral affect of surprise-startle, the negative affects of fear-terror, distress-anguish, and anger-rage, as well as the negative affect auxiliaries of dismissal, disgust, and shame-humiliation.' The subjective experience of these affective states is not simply the result of the activation of these pathways. When analyzed in these terms, shame-humiliation is an innate reaction that functions primarily to reduce facial communication. It includes lowering the eyes and head, as well as blushing. ${ }^{24}$ In contrast, shame is a subjective experience that develops as other components render innate physical sensations of the affect meaningful. Malin ${ }^{10}$ prefers to change the first definition into inhibition-withdrawal to describe the innate response, and reserves the term emotion for describing the experience of shame."

\section{THE ATTACHMENT RELATIONSHIP: EMOTIONAL SHAPING OF THE BRAIN page 44}

"A poor attachment relationship might create an unbalanced right/left hemisphere development, which in turn might play an important role in vulnerability to psychopathology. Hemispheric organization abnormalities have been found in several psychiatric disorders, such as schizophrenia, mania, and autism, as well as in individuals at risk for psychiatric disorders. Abnormalities of dopamine levels in the right hemisphere have been found in association with altered emotionality soon after birth following prenatal stress. Electrophysiologic data have shown abnormal right-frontal activation in 10-month-old infants with high levels of distress to maternal separation. In both infants and adults, this asymmetry is associated with vulnerability to psychopathology. A right hemisphere dysfunction has been reported in children with nonverbal learning disabilities and with a developmental right-hemisphere syndrome involving maladaptation to new situations, difficulties in relationships with peers, and extreme shyness. It has been found that an underactivation of the right and/or hyperactivation of the left brain is associated with a high degree of physical health complaints, alexithymia, and panic disorder." 


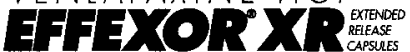

Brief Summary

Indications and Usage: Effexor XR is indicated for the treatment of depression and for the treatment of Generalized AnXiety Disorcer (GAD). Concomitant use in patients taking monoamine oxidase inhibitors (MAOIS) is contraindicated (see "Warnings"), which were serious, have been reported in patients who have recently been discontinued from an MAOI and started on venlafaxine, or who have recentty had venlafaxine therapy discontinued prior to initiation of an
MA0l. These reactions have included tremor, myoctonus, diaphoresis, nausea, vomiting, flushing, dlzziness, hyperthemia with features resembling neuroleptic malignant syndrome, seizures, and death. In patients MAO1, there have also been reports of serious, sometimes fatal, reactions. For a selective serotonin reuptake inhibitit, these reactions have included hyperthememia, rigidity, myoctonus, autonomic instability with possible rapid fluctuations of vital signs, and mental status changes that include extreme agitation progressing to delirium and coma. Some cases presented with features resembling neuroleptic malignant syndrome. Severe cyclic antidepressants and MAOls. These reactions have also been reported in patients who have recently discontinued these drugs and have been started on an MAOI. The effects of combined use of venlafaxine and norepinephrine and serotonin reuptake, it is recommended that Effexar XR (venlafaxe ine an inhibiochloride) extended release capsules not be used in combination with an MAOI, or within at least 14 days of discontin
ing treatment with an MAOI. Based on the hali-life of venlataxine, at least 7 days should be allowed after stopping venlafaxine before starting an MAOI.

SUSAANNED HYPERTENSION-Venlafaxine is associated with sustained increases in blood pressure in some patients.
Among patients teated with $75-375 \mathrm{mg}$ per day of Effexor XR in premarketing depression studiles. $3 \%$ experienced Among patients teated with 75-375 mg per day of Effexor XR in premarketing depression stidies, $3 \%$ experienced
sustained hypertension (defined as treatment-emergent supine diastolic blood pressure (SDBP) $\geq 90$ mm Hg and $\geq 10 \mathrm{~mm} H \mathrm{Hg}$ above baseline for 3 consecutive on-therapy visits]. Among patients treated with $75-225 \mathrm{mg}$ per day of
Effexor $\mathrm{XR}$ in premarketing GAD studies, $0.4 \%$ (2/476) experienced sustained hypertension. Experience with immediate release venlataxine showed that sustained hypertension was dose related, increasing from $3-7 \%$ at $100-300 \mathrm{mg}$, $>300 \mathrm{mg} / \mathrm{day}$ to tully evaluate the incidence of sustained blood pressure at these higher doses. In premarketing depression and GAD studies, $0.7 \%$ and $0.4 \%$ of the Effexor XR-treated patients, respectively, discontinued treatment because of elevated blood pressure. It is recommended that patients receiving Effexor XR have regular monitoring of
blood pressure. For patients who experience a sustained increase in blood pressure, either dose reduction or discon-

Precautions: GENERAL —Insomnia and Nervousness. Treatment-emergent insomnia and nervousness have been reported for patients treated with Effexor $X R$. Insomnia and newousness each led to drug discontinuation in $0.9 \%$ of led to drug discontinuation in $5 \%$ and $3 \%$, respectively, of the patients treated with Effexor $X R$

Changes in AppetiteWeight Treatment-emergent ancrexia has been reported in short-term depression and anxiety

patients in placebo-controlled depression trials. A loss of $7 \%$ or more of body weight occurred in $3 \%$ of the Effexor XRteated and $0 \%$ of the placebo-treated patients in placebo-contored of

Activation of Mania/thyomania: Mania or hypomanla has occurred during short-term depression studies. Effexor XR should be used cautiously in patients with a history of mania. Seizures: No seizures oocurred among Effexor XR-treated patients in short-term trials. In all premarketing depress
trials with Effexor, seizures were reported in $0.3 \%$ of venlafaxine-treated patients. Use Effexor XR cautiously in patients with a history of seizures. Discontinue in any patient who develops seizures.

Suicide. The possibility of a suicide attempt is interent in depression and may persist until significant remission occurs. smallest quantity of capsules consistent with good patient management to reduce the risk of overdose. The same precautions observed when treating patients with depression should be observed when teatung patents whe cad temic illness is limited. Use Effexor XR cautiously in patients with diseases or conditions that could affect hemodynamic responses or metabolism. Venlafaxine has not been evaluated in patients with recent history of Ml or unstable heart disease. In short-term depression studiles electrocardlographic changes in corrected QT interval (QTC) for heart rate for Effexor XR-treated patients was 4 beats per minute. In short-term GAD studies, mean changes in QTC for Effexor XR-treated patients did not differ significantly from placebo. The mean change from baseline heart rate for
Effexor XR-treated patients in anxiety studies was 3 beats per minute. The clinical significance of these changes is unknown. In patients with renal impaiment (Ge the prolong

Sary; use with caution in such patients.
INFORMATION FOR PATIENTS - Clinical studies in healthy individuals revealed no clinically significant impairment of

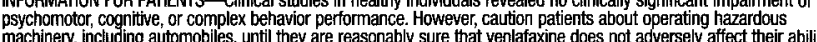
ties. Tell patents to 1) notify their physician if they become pregnant or intend to become pregnant during therapy or if they are nursing; 2 inform physician about other prescription or over the counter medications they are taking or
plan to take; 3) avoid alcohol while taking Effexor $X R ; 4$ ) notify their physician if they develop a rash, hives, or related LABORATORY TESTS: There are no specific laboratory tests recommended

DRUG INTERACTIONS - Cimetidine: Use with caution when administering venlafaxine with cimetidine to patients with

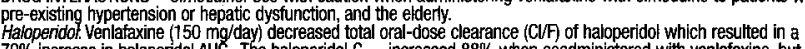
$70 \%$ increase in haloperidol AULC. The haloperidol $\hat{G}_{\text {max }}$ increased $88 \%$ when coadministered with venlafaxine, but the haloperidol elimination half-life was unchanged.
Drugs Inhibiting Cytochrome $P 450206$ Metabolism. Venlafaxine is metabolized to its active metabolite, 0 -desmethyvenlafaxine (ODV), via cytochrome P4502D6. Drugs inhibiting this isoenzyme have the potential to increase plasm venlafaxine and ODV are essentially unchanged in CYP2D6 poor metabolizers, no dosage adjustment is required when venlafaxine is coadministered with a CYP2D't inhibitor. primary metabolizing enzymes for ventafaxine, has not been studied. Thereforibits both CYP2D6 and CYP3A4, the therapy include venlafaxine and any agent(s) that produce simultaneous inhibition of these two enzyme systems. Dugs Metabolized by Cytochrome P450 lsoenzymes. Studies indicate that venlafaxine is a relatively weak inhibitar of
CYP2D6. Venlafaxine did not inhibit CYP1A2 and CYP3A4 (in vito and in vivo), CYP2C9 (in vitro, or CYP2C19 (in vivo). Imipramine- Venlataxine did not affect the pharmacokjnetics of imipramine and 2-OH-imipramine. However, increased by $2.5-4$. mold. Imipramine did not affect the pharmacokinetics of venlataxine and ODV. The clinical significance of elevated 2-OH-desipramine levels is unknown.
Alsperidone-Venlafaxine administered under steady-state conditions at $150 \mathrm{mg} /$ day slightly inhibited the CYP2D6mediated metabolism of risperidone (administered as a single $1 \mathrm{mg}$ oral dose) to its active metabolite, 9 -hydroxynisperidone, resulting in an approximate $32 \%$ increase in risperidone AUC. However, venlataxine coadministration dic
not significantuly alter the pharmacokinetic profile of the total active molety (risperidone plus 9 -hydroxyrisperidone). CNS-Active Drugse Use of venlafaxine with CNS-active drugs has not been systematically evaluated; use caution when
administering Elfoxor XR with such drugs.

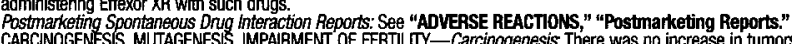
18-month studies in mice given up to 120 mg/kg/day [1.7 times the maximum recommended human dose (MRHD) $\mathrm{mg} / \mathrm{m}^{2}$ basis] or in $24-$ month studies in rats given up to $120 \mathrm{mg} / \mathrm{kg} /$ day.

Mutagenesis. Venlafaxine and OOV were not mutagenic in the Ames reverse mutation assay in Salmonella bacteria or the Chinese hamster ovary/HGPRT mammalian cell forward gene mutation assay. Venlataxine was not clastogenic in
several assays. ODV elicited a clastogenic response in the in vivo chromosomal aberation assay in rat bone marrow.
Impaimment of Fentifity. No effects on reproduction or fertility in rats were noted at oral doses of up to 2 times the MRHD on a mg/m ${ }^{2}$ basis.
PREGNANCY - Teratogenic Effects-Pregnancy Category $C$. Reproduction studies in rats given 2.5 times, and rabbits given 4 times the MRHD (mg/ $m^{2}$ basis) revealed no maflormations in offspring. However in rats given 2.5 times the MAHD, there was a decrease in pup weight, an increase in stillborn pups, and an increase in pup deaths during the
fisst 5 days of tactation when dosing began during pregnancy and continued until weaning. There are no adequate and weil-contoolled studies in pregnant women; use Effexor XR during pregniancy only if clearly needed. been reported to be excreted in human milk. Because of the potential for serious adverse reactions in nursing infant from Effexor XR, a decision should be made whether to discontinue nursing or to discontinue the drug, taking into account the importance of the drug to the mother.
PEDIATRIC USE-Safety and effectiveness in pediatric patients have not been established.

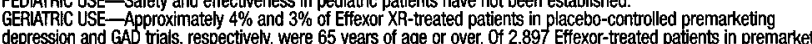
depression and GAD trials, respectively, were 65 years of age or over. Of 2,897 Effexor-treated patients in premarket-
ing phase depression studies, $12 \%$ were 65 years of age or over. No overall differences in effectiveness or safety were observed between geriatric patients and younger patients. However, greater sensitivity of some older individuals antidiuretic hormone secretion (SIADH) have been reported uSUaly in the elderly.
Adverse Reactions: ASSOCLATED WTH DISCONTINUATION OF TREATMENT - Approximately $11 \%$ and $23 \%$ of Effexor XR



of placebo in depression trials included: nausea, anorexia, dry mouth, dizziness, insomnia, and somnolence; in U.S.
placebo-controlled depression trials included: hypertension, diarhea, paresthesia, tremor, abnormal (mosty blurred) vision, and abnormal (mostly delayed) ejaculation; in GAD trials included: headache, asthenia, vasodilation, nausea, INCIDENCE IN CONTROLLED TRIALS - Commonly Observed Adverse Events in Controlled Clinical Irials: The most commonly observed adverse events associated with the use of Effexor XR in placebo-controlled depression triats
(incidence of $5 \%$ or greater and incidence for Effexor XR at least twice that for placebo): nausea (31\% vs. 12\%), dizz-

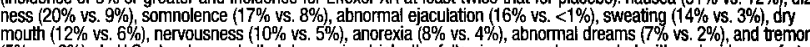
(5\% vs. $2 \%)$. In U.S. placebo-controlled depression trials, the following were also reported with an incidence of at nia, nervousness, tremor, abnermal vision, hypertension, vasodilation, and yawning. The most commonily observed adverse events associated with the use of Effexor XR in placebo-controlled GAD tials (incidence of $5 \%$ or greater and
incidence for Effexor XR at least twice that for placebo): nausea (43\% vs. 11\%), dry mouth (23\% vs. 5\%), insomnia

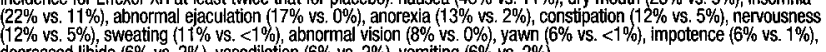
Adverse Events $O$ Occurring at an incidence of $2 \%$ or More Among Effexor $X R$ - ireated Patients. The following occurred in short-term, placebo-controlled depression trials (up to 12 weeks) with doses of 75 to $225 \mathrm{mg} / \mathrm{day}$, at a trequency of $2 \%$ or more, and greater than placebo. Body as a Whole: asthenia. Cardiovascular, vasodilation, hypertension. dizziness, somnolence, insomnia, dry mouth, , nervousness, abnormal dreams, tremor, deperession, paresthesia,
decreased libido, agitation. Respiratory System: phanyngtits, yawn. Skin: sweating. Special Senses: abnorma decreased libici, agitation. Respiratory System: pharyngitis, yawn. Skin: sweating. Special Senses: abnormal
vision. Urogenital System: abnormal ejaculation, impotence, anorgasmia (female). The following occurred in shortterm, placebo-controlled GAD trials (up to 8 weeks), with doses of 75 to $225 \mathrm{mg}$ /day, at a frequency of $2 \%$ or more Gardiovascular: vasodilation, tachycardia. Digestive: nausea, anorexia, dianhea, constipation, vomiting, flatulence. Musculoskeletal System: myalgia. Nervous System: dry montuth, insomnia, dizziness, somnolence, nervousnness,
decreased libido, abnormal dreams, tremor, paresthesia thinking abnormal, trismus, twitching. Respiratory System mintis, yawn, cough increased. Skin: sweating. Special Senses: abnormal vision. Urogenital System: abnormal ejaculation, impotence, dysmenomhea, orgasmic dystunction (female), urinary frequency

Vital Sign Changes in clinical depression and GAD trials, Effexor XR was associated with a mean increase in pulse rate
of about 2 beats/min. (See the "Sustained Hypertension" section of "Warnings" for effects on blood pressure) Laboratory Changes. In clinical depression and GAD tials, Effexor XR was associated with a mean increase in serum cholesterol concentration of about $1.5 \mathrm{mg} / \mathrm{dL}$ and $2.5 \mathrm{mg} / \mathrm{dL}$, respectively; clinical significance is uniknown. ECG Changes. (See the "Use in Patients With Concomitant Illnesses" section of "Precautions") marketing assessment, multiple doses of Effexor XR or Effexor were administered to 4174 patients, and the following adverse events were reported. Note: "frequent" = events occurring in at ieast 1/100 patients; "infrequent" = $1 / 100$ to 1/1000 patients; " "rare" = fewer than $1 / 1000$ patients. It is important to emphasize that although the events occurred
during teatment with venlafaxine, they were not necessarily caussed by it.
Body as a whole - Frequent chest pain substemal; Infrequent: face edema, intentional injury, malaise, monillasis Body as a whole - Frequent: chest pain substemal; Infrequent: face edema, intentional injury, malaise, moniliasis, al syndrome. Cardiovascular system - Frequent: migraine, postural hypotension; Infrequent angina pectoris, arrthyth mia, extrasystoles, hypotension, peripheral vascular disorder (mainly cold feet and/or cold hands), syncope, throm-
bophlebitis; Rare: arteritis, first-degree atrioventricular block, bigeminy, bradycardia, bundle branch block, cerebral ischemia, coronary artery disease, congestive heart failure, heart arrest, mitral valve disorder, mucocutaneous hemor-
thage, myocardial infarct, pallor. Digestive system - Frequent enuctation, increased appetite; Infrequent bruxism, Inage, myocardial infarct, pallor. Digestive system - Frequent enuctation, increased appetite; Infrequent bruxism, hemorthage, hemorntoids, melena, stomatitis, mouth ulceration; Rare: cheilitis, cholecystitis, cholelithiasis. hematemesis, gastrointestinal hemornage, gum hemorrtage, hepattis, ileitis, jaund cce, intestinal obstruction, oral roidism, hypottyyoidism, thyroid nodule, thyroiditis. Hemic and lymphatic system - Frequent ecchymosis; Injtrequent

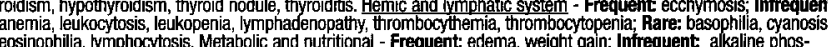
phatase increased, glycosuria, hypercholesteremia, hyperglycemia, hyperuricemia, hypoglycemia hypokalemia, SGOT ncreased, thirst; Rare: alcohol intolerance, bilirubinemia, BUN increased, creatinine increased, diabetes melituss, dehydration, gout, hemochromatosis, hypercalcinuria, hyperkalemia, hyperlipemia, hyperphosphatemia, hyponatremia,
hypophosphatemia, hypoproteinemia, SGP increased, uremia. Musculoskeletal system - Frequent artiralgia; hypophosphatemia, hypoproteinemia, SGP increased, uremia. Musculoskeletal system - Frequent arthralgia; amnesia, confusion, depersonalization, emotional lability, hypesthesia, vertigo; Infrequent: apathy, ataxia circumoral

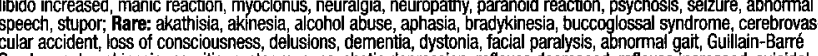
cular accident, loss of consciousness, delusions, dementia, dystonia, facial paralysis, abnormal gair, Guillain-Barre deation, torticollis. Respiratory system - Frequent dyspnea: Infrequent: asthma, chest congestion, epistaxis, hyperventilation, laryngismus, laryngitis, pneumonia, voice alteration; Rare: atelectasis, hemoptysis, hypoventilation, hypo-
a, pleurisy, pulmonary embolus, sleep apnea. Skin and appendages - Frequent rash, pruritus; infrequent, acre, alopecia, brittle nails, contact dermattis, dry skin, eczema, skin hypertrophy, maculopapular rash, psonasis, urticaria; Rare: erythremia nodosum, exfoliative dermatitis, lichenoid dermatitis, hair discoloration, skin discoloration, , turunculosis, hirsutism, leukoderma, pustular rash, vesiculobullous rash, seborrthea, skin atrophy, skin striae. Special senses -

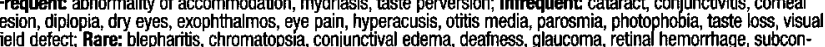
unctival hemonthage, keratititis, labyrinthitis, miosis, papilledema, decreased pupillary reflex, ottitis externa, scleritis,

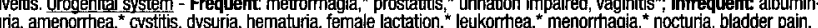

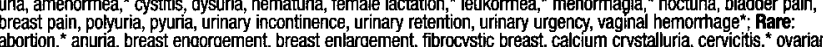
abortion," anuria, breast engorgement, breast enlargement, fibrocystic breast, calcium crystalluria, cervicitis," ayst," prolonged erection, , gynecomastia (male), ${ }^{*}$ hypomenonhea, ${ }^{*}$ kidney calculus, kidney pain, kidney function spasm.* ("Based on the number of men and women as appropriate.)
Postunarketing Reports: Voluntary reports of other adverse events temporally associated with the use of Effexor (the Postunarketing Reports: Voluntary reports of other adverse events temporally associated with the use of Effexor (the
mmediate release form of ventafaxine) that have been received since market introduction and that may have no causal relationship with the use of Effexor include the following: agranulocytosis, anaphylaxis, aplastic anemia, catato-
nia, congentital anomalies, CPK increased, deep vein thrombophebitis, delirium, EKG abnormalites (such as atrial fibJohon, supraventricular tachycardia, ventricular extrasystoles, ventricular tachycardia), epidermal necrosis/stevens-
Johnson Syndrome, erythema mutifiorme, extrapyramidal symptoms (including tardive dyskinesia), hemonhage including eye and gastrointestinal bleeding), hepatic events (including $\mathrm{GGT}$ elevation; abnormalitites of unspectfied roleptic malignant syndrome-like events (including a case of a 10 -year-old who may have been taking

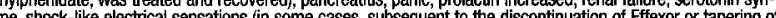
dose), and syndrome of inappropriate antidiuretic hormone secretion (usually in the elderly).
There have been reports of elevated clozapine levels that were temporally associated with adverse events, including
seizures, following the addition of venlafaxine. There have been reports of increases in prothrombin time, partial thromboplastin time, or INR when venlataxine was given to patients receiving warfarin therapy.

Drug Abuse and Dependence: Effexor ${ }^{6}$ XR is not a controlled substance. Evaluate patients carefully for history of ance, incrementation of dose, drug-seeking behavior). OVERDOSAGE: In premarketing evaluation of Effexor XR for depression, there were 2 reports of acute overdosage $6 \mathrm{~g}$ of Effexor XP with $2.5 \mathrm{mg}$ of lorazepam, and $2.85 \mathrm{~g}$ of Effexor XR). Both recovered without sequelae. In recovered without sequel of Effexor, there were 14 reports of acute overdosage (highest dose was $6.75 \mathrm{~g}$ ). All patients generalized convulsions, prolongation of QTc to $500 \mathrm{msec}$ (compared with $405 \mathrm{msec}$ at baseline) in one case, and mild sinus tachycardia. In premarketing evaluation of Effexor XR for GAD, there were 2 reports of acute overdosage $10.75 \mathrm{~g}$ of Effexor

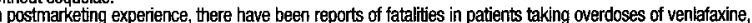
oredominantly in combination with alcohol and/or other drugs.

reatment should consist of those general measures employed in the management of overdosage with any General supportive and symptomatic measures are also recommended. Induction of emesis is not recommended. performed soon after ingestion or in symptomatic patients. Activated charcoal should be administered. Due to
the large volume of distribution of this drug, forced diuresis, dialysis, hemoperfusion, and exchange transfusion are unlikely to be of benefit. No specific antidotes for venlafaxine are known. In managing overdosage, consider the possibility of muitiple drug involvement. The physician should consider contacting a polson coison control centers are listed in the Physicians' Desk Reference
SWITCKING PATIENTS TO OR FROM A MONDAMINE OXIDASE INHIBITOR: At least 14 days should elapse between discontinuation of an MAOI and initiation of therapy with "Effexor XR. In addition, at least 7 days should be allowed Please consult full prescribing information for detalied dosing instructions.

Please consult full prescribing information for detailed dosing instructions.
This brief summary is based on the circular 4876-4, issued March 22, 1999.

WName

2000, Wyeth-Ayerst Laboratories 


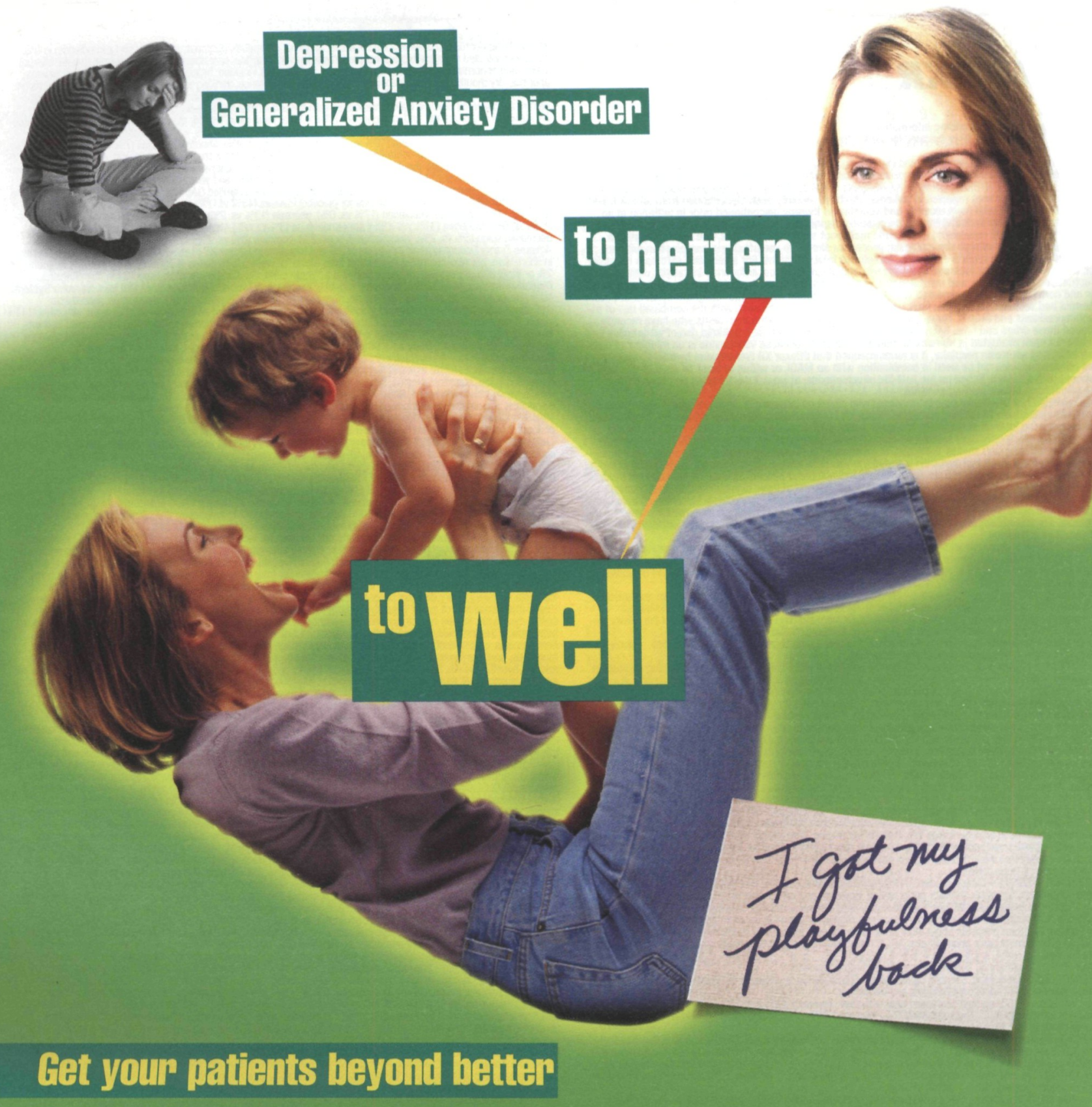

- Working on both serotonin and norepinephrine, the unique formulation of EFFEXOR XR offers more of your patients the ability to achieve remission-full symptom resolution. ${ }^{1,2}$

\section{Need proof? Call 1-888-EFFEKOR XR.}

Visit us at www.EFFEXORXR.com

Please see brief summary of Prescribing Information on the next page.

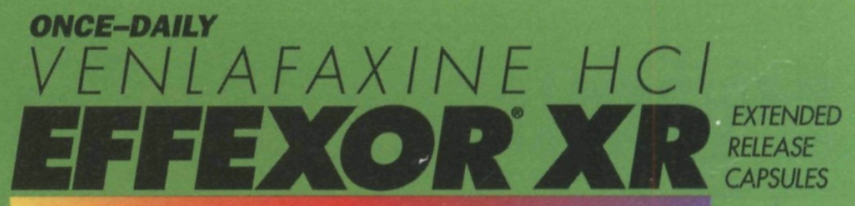

\section{Beyond better.}

The efficacy and safety of EFFEXOR XR for pediatric use have not been established.

EFFEXOR XR is contraindicated in patients taking monoamine oxidase inhibitors (MAOIs). EFFEXOR XR should not be used in combination with an MAOI or within at least 14 days of discontinuing treatment with an MAOI; at least 7 days should be allowed after stopping EFFEXOR XR before starting an MAOI.

The most common adverse events reported in EFFEXOR XR placebo-controlled depression trials (incidence $\geq 10 \%$ and $\geq 2 \times$ that of placebo) were nausea, dizziness, somnolence, abnormal ejaculation, sweating, dry mouth, and nervousness; and in GAD trials were nausea, dry mouth, insomnia, abnormal ejaculation, anorexia, constipation, nervousness, and sweating. Treatment with venlafaxine is associated with sustained increases in blood pressure (BP) in some patients. Three percent of EFFEXOR XR patients in depression studies (doses of 75 to $375 \mathrm{mg} /$ day) and $0.4 \%$ in GAD studies (doses of 75 to $225 \mathrm{mg} /$ day) had sustained $\mathrm{BP}$ elevations. Less than $1 \%$ discontinued treatment because of elevated $\mathrm{BP}$. Regular $\mathrm{BP}$ monitoring is recommended.

References: 1. Data on file, Wyeth-Ayerst Laboratories, Philadeliphia, Pa. 2. Ferier IN. Treatment of major depression: is improvement enough? J Cin Psychiaty. 1999;60(suppl 6):10-14. 


\section{Table of Contents}

FeatureArticles

18 Introduction-Neuroscientific Approach to Emotions and Feelings: The Last Frontier of the New Millennium

By Donatella Marazziti, MD

\section{Libido and Hormones}

By Domenico Canale, MD, and Stefania Pistoia, MD

24 Psychobiology of Boredom

By Carlo Maggini, MD

28 Shame and Psychopathology

By Stefano Pallanti, MD, and Leonardo Quercioli, MD

44 Emotions, Brain Development, and

Psychopathologic Vulnerability

By Silvana Galderisi, MD, PhD, and Armida Mucci, MD, PhD

\section{ORIGINAL RESEARCH}

61 The Obsessive-Compulsive Spectrum:

A Survey of 800 Practitioners

By Eric Hollander, MD, Rebecca Twersky, MD, and Carol Bienstock

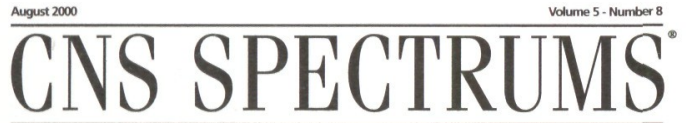

The International Journal of Neuropsychiatric Medicine

$$
8
$$

Neuroscientific Approach to

Emotions and Feelings:

The Last Frontier of the New Millennium

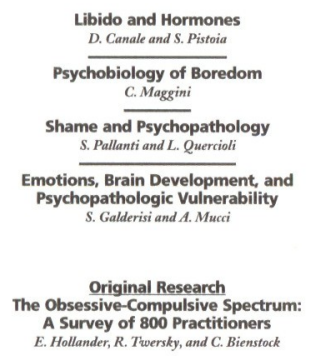

$\overline{\text { CNS SPECTRUMS }}$

The International Journal of

Neuropsychiatric

Medicine

Volume 5 - Number 8

August $\mathbf{2 0 0 0}$

CNS Spectrums is a peer review journal and is indexed in EMBASE/Excerpta Medica, DIALOG, SilverPlatter, OVID, and Lexis-Nexis. CNS Spectrums is endorsed by, and is the official journal of, the International Neuropsychiatric Association, with members in 30 countries.

\section{CNS Spectrums}

(ISSN 1092-8529)

is published monthly by MBL Communications, 665 Broadway, Suite 805 . New York, NY 10012-2302.

Periodicals postage paid at New York, NY, and at additional mailing offices.

One year subscription rates: domestic $\$ 90$;

foreign $\$ 145$;

in-training $\$ 50$.

For subscriptions:

Fax: 212-328-0600.

E-mail:

jpl@medworksmedia.com

Postmaster:

Send address changes to CNS Spectrums

clo PPS Medical Marketing Group 264 Passaic Ave.

Fairview, NJ 07004-2595 
$\overline{\text { CNS SPECTRUMS }}$

The International Journal of

Neuropsychiatric Medicine

Volume 5 - Number 8 August 2000

\section{Table of Contents}

Departments/Monthly Columns

POINT \& COMMENTARY

13 Human Emotions (Lust, Boredom, and Shame) and Brain Development

By Eric Hollander, MD

THE NEUROLOGY OF BEHAVIOR

14 The Contemporary Relevance of Neuropsychiatry

By Michael Trimble, MD, FRCP, FRPsych

FIRST PERSON

15 Depression and Comorbid Medical Disorders:

A Reversal of Causality

By Steven P. Roose, MD

CNS NEWS

16 Briefs from the Fields of Neurology \& Neuropsychiatry

GRAND ROUNDS

49 HIV-1-Associated Cognitive-Motor Disorders:

A Research-Based Approach to Diagnosis and Treatment

By Karl Goodkin, MD, PhD, Frances. L. Wilkie, PhD, Teri T. Baldewicz, PhD, Mauricio Concha, MD, Mary D. Tyll, PhD, Charles J. LoPiccolo, MD, and Paul Shapshak, PhD

\section{CONTINUING MEDICAL EDUCATION}

67 This continuing medical education series gives the reader the opportunity to test his/her understanding and recall of clinical material presented in this issue. Approved for 3.0 credit hours in Category 1.

INDICES

70 By subject and author

For editorial and advertising inquiries, please fax 212-328-0600.

Opinions and views expressed by authors are their own and do not necessarily reflect the views of the publisher, MBL Communications, or the editorial advisory board. Advertisements in CNS Spectrums are accepted on the basis of adherence to ethical medical standards, but acceptance does not imply endorsement by CNS Spectrums, or the publisher.

CNS Spectrums@ is a registered trademark of CNS Spectrums, LLC, New York, NY. CNS News $^{\mathrm{TM}}$ is a trademark of MBL Communications, Inc., New York, NY.

Permission to reproduce articles in whole or part must be obtained in writing from the publisher.

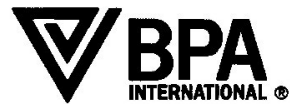
INTERMATIONAL Copyright $\odot 2000$ by MBL Communications. All rights reserved. Printed in the United States. 


\section{Risperdal tablets and
orol solution $1 \mathrm{mg} / \mathrm{mL}$}

\section{BEFORE PRESCRIBING, PLEASE CONSULT COMPLETE PRESCRIBING} INFORMATION OF WHICH THE FOLLOWING IS A BRIEF SUMMARY. INDICATIONS AND USAGE

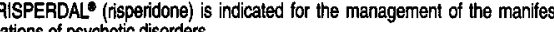
CONTRAINDICATIONS

RISPERDAL (risperidone) is contraindicated in patients with a known hype WARNINGS

Neuroleptic Mallgnant Syndrome (NMS)

A potentially fatal symptom complex sometimes referred to as Neuroleptic Malignant Syndrome (NMS) has been reported in association with antipsychotic drugs. If a patient requires antipsychotic drug treatment after recovery
from NMS, the potential reintroduction of drug therapy should be carefully from NMS, the potential reintroduction of diug therapy should be carefully NMS have been reported.

\section{Tardke Dyskinesia}

A syndrome of potentially irreversible, involuntary, dyskinetic movements may dovelop in patients treated with antipsychotic drugs. Whether antipsycho

If signs and symptoms of tardive dyskinesia appear in a patient on RISPERDAL: drug discontinuation should be considered. However, some patients may require
treatment with RISPERDAL

Potential for Proarrhythmic Effects: Risperidone and/or 9-hydroxyrisperidone appears to lengthen the QT interval in some patients, although there is no average increase in treated patients, even at $12-16 \mathrm{mg}$ /day, well above
the recommended dose. Other drugs that prolong the QT interval have been associated with the occurrence of torsades de pointes, a life-threatening armthmia Bradycardia, electrolyte imbalance, concomitant use with othe drugs that prolong QT, or the presence of congenital prolongation in QT can drugs that prolong QT, or the presence of congen PRECAUTIONS

General

Orthostatic Hypotension: RISPERDAL (risperidone) may induce orthostatio hypotension associated with dizziness, tachycardia, and in some patients, syncope, especially during the initial dose-titration period, probably reflecting its alpha-adrenergic antagonistic properties. Syncope was reported in $0.2 \%$
$6 / 2607$ of RISPERDAL treated patients in phase $2-3$ studies. The risk o orthostatic hypotension and syncope may be minimized by limiting the initi dose to $2 \mathrm{mg}$ total (either QD or $1 \mathrm{mg}$ BID) in nomal adults and $0.5 \mathrm{mg} B I D$ the elderiy and patients with renal or hepatic impairment (See DOSAGE AN ADMINISTRATION). Monitoring of orthostatic vital signs should be considered in patients for whom this is of concern. A dose reduction should be considere if hypotension occurs. RISPERDAL should be used with particular caution in patients with known cardiovascular disease (history of myocardial infarction or ischemia, heart failure, or conduction abnormalities), cerebrovascular disease and conditions which would predispose patients to hypotension e.g., dehydration and hypovolemia. Clinically significant hypotension has been obsen

Solzures: RISPERDAL should be used cautiously in patients with a history of seizures.

Oysphagla: Esophageal dysmotility and aspiration have been associated with antipsychotic drug use. Aspiration pneumonia is a common cause of morbidity and mortality in patients with advanced Alzheimer's dementia. RISPERDAL and other antipsychotic

Hyperprolactinemia: As with other drugs that antagonize dopamine $D$ receptors, risperidone elevates prolactin levels and the elevation persist during chronic administration. Neither clinical studies nor epidemiologic administration of this class of drugs and tumorigenesis in humans; the available evidence is considered too limited to be conclusive at this time.

Potential for Cognittve and Motor Impaiment: Somnolence was a common reported adverse event associated with RISPERDAL treatment, especially when ascertained by direct questioning of patients. This adverse event is dose related. Patients should be cautioned about operating hazardous machinery therapy does not affect them adversely.

Priaplem: Rare cases of priapism have been reported.

Thrombotic Thrombocytopenic Purpure (TTP): A single case of TTP was reported in a 28 year-old female patient receiving RISPERDAL in a large, onced jinndica, enced jaundice, tever, and bruising, but eventually recovered after recer Antemetic eflect: Risperidons has an antiemetic effect in animals; this eflect may also occur in humans, and may mask signs and symptoms of overdosage with certain drugs or of con

Bocty Temperature Regulation: Disruption of body temperature regulation has been attributed to antipsychotic agents. Caution is advised when prescribing for palients who wit be exposed to temperature extremes. Sulclde: The possibility of a suicide attempt is inherent in schizophrenia, and ciose supervision of high risk patients should accompany drug therapy.

Use in Patients with Concomitant IIIness: Clinical experience with imited. Caution is advisable in using RISPERDAL in patients with diseases or conditions that could aflect metabolism or hemodynamic responses. Because of the risks of orthostatic hypotension and QT prolongation, caution Increased plasma concentrations of risperidone and 9-hydroxyrisperidone occur in patients with severe renal impairment and in patients with severe hepatic impaiment. A lower starting dose should be used in such patients. Information for Patients

Physicians are advised to consult full prescribing information to review issues to be discussed with patients for whom they prescribe RISPERDAL ${ }^{\circ}$ Drug interactlons

The interactions of RISPERDAL ${ }^{\circ}$ and other drugs have not been systematically evaluated. Given the primany CNS effects of risperidone, caution should be used when RISPERDAL is taken in combination with other centrally acting drugs and alcohol. RISPERDAL may antagonize the effects of levodopa an may increase the clearance of risperidone. Chronic administration of clozapine may increase the clearance of risperidone. Chronic administ
with risperidone may decrease the clearance of risperidone.

Fluoxetine may increase the plasma concentration of the anti-psychotic fraction (risperidone plus 9-hydroxyrisperidone) by raising the concentration of rispen-
done, although not the active metabolite, 9 -hydroxyrisperidone.
Drugs that Inhlbit Cytochrome $P_{2} 110$, and Other $P_{\text {lo }}$ lsozymes: Risperidone is metabolized to 9-hydroxyrisperidone by cytochrome $P$, psychotropic and other drugs (See CLNICAL PHARMACOLOG a variety of actions that reduce the metabolism of risperidone to 9 -hydro). Drug interwould increase the plasma concentrations of risperidone and lower the concentrations of 9 -hydroxyrisperidone. Analysis of clinical studies involving a modest number of poor metabolizers $(n \approx 70)$ does not suggest that poor and extensive metabolizers have different rates of adverse

In vitro studies showed that drugs metabolized by other $P_{\infty}$ isozymes, including Drugs Metabolized by Cytochrome $P_{w} I I D_{i}$ : In vitro studies indicate that risperidone is a relatively weak inhibitor of cytochrome $P_{m, n} \|_{\text {s. }}$. Therefore RISPERDAL is not expected to substantially inhibit the clearance of drugs that are metabolized by this enzymatic

\section{confirm this expectation are not available.}

Carcinogenesis: Carcinogenicity studies were conducted in Swiss albino mice and Wistar rats. Risperidone was administered in the diet at doses of $0.63,2.5$ and $10 \mathrm{mg} / \mathrm{kg}$ for 18 months to mice and for 25 months to rats. These doses are equivalent to 2.4, 9.4 and 37.5 times the maximum human dose (16 mg/day) on a mg/kg basis or $0.2,0.75$ and 3 times the maximum human dose (mice) or were statistically significant increases in pituliary gland adenomas, endocrine pancreas adenomas and mammary gland adenocarcinomas.

These findings are considered to be prolactin medicated. The relevance for human risk of the findings of prolactin-mediated endocrine tumors in rodent Mutagenesis: No evidence of mutagenic potential for risperidone was found Impairment of Fertility: Risperidone $(0.16$ to $5 \mathrm{mg} / \mathrm{kg})$ was shown to impair mating, but not fertility, in Wistar rats in three reproductive studies at doses 0.1 to 3 times the maximum recommended human dose on a $\mathrm{mg} / \mathrm{m}^{2}$ basis. Pregnancy

Pregnancy Category $\mathrm{C}$ : There are no adequate and well-controlled studies

RISPERDAL should be used during pregnancy only if the potential benefit ustifies the potential risk to the fetus.

Labor and Delivery

Nursing Mothers

It is not known whether or not risperidone is excreted in human milk. Women receiving RISPERDAL ${ }^{\oplus}$ should not breast feed.

Pediatric Use

Gerlatric Use

Clinical studies of RISPERDAL did not include sufficient numbers of patients aged 65 and over to determine whether they respond differently from younger patients. Other reported clinical experience has not identified differences in responses between elderly and younger patients. In general, a lower starting dose is recommended for an elderty patient, reflecting a decreased phamacokinetic is recommended for an elderly patient, reflecting a decreased phammacokinetic
clearance in the elderly, as well as a greater frequency of decreased hepatic, clearance in the elderly, as well as a greater frequency of decreased hepatic,
renal, or cardiac function, and of concomitant disease or other crug therapy
(See CLINICAL PHARMACOLOGY and DOSAGE AND ADMINISTRATION). While elderty patients exhibit a greater tendency to orthostatic hypotension, its risk in the elderly may be minimized by limiting the initial dose to $0.5 \mathrm{mg}$ BID followed by careful titration (See PRECAUTIONS). Monitoring of of This drug is known to be substantially excreted by the kidney, and the risk This drug is known to substantially excreted by the kidney, and the risk function. Because elderly patients are more likely to have decreased renal unction, care should be taken in dose selection, and it may be useful to monitor ADVERSE REACTIONS

Associated with Discontinuation of Treatment

Approximately $9 \%$ percent (244/2607) of RISPERDAL (risperidone)-treated patients in phase 2-3 studies discontinued treatment due to an adverse event, compared with about $7 \%$ on placebo and $10 \%$ on active control drugs. The more common events $(20.3 \%$ ) associated with discontinuation and considered to be possibly or probably drug-related includec:

dizziness, hyperkinesia, somnol

Commonly Observed Adverse Events in Controlled Clinical Trials: In two 6 - to 8-week placebo-controlled trials, spontaneously-reported, traatmentemergent adverse events with an incidence of $5 \%$ or greater in at least one of he RISPERDAL groups and at least twice that of placebo were: anxiety, dyspepsia, thinitis, rash, and tachycardia.

Adverse events were atso elicited in one of these two trials (i.e. in the fixeddose trial comparing RISPERDAL ${ }^{*}$ at doses of 2,6 , 10, and $16 \mathrm{mg}$ day with placebo) utidizing a checklist for detecting adverse events, a method that is more sensitive than spontaneous reporting. By this method, the following additional common and drugrelated adverse events were present at least $5 \%$ and twice the rate of placebo: increased dream activity, increased duration of and twice the rate of placebo: increased dream activity, increased duration of bances, diarmea, weight gain, menorntragia, diminished sexual desire, erectile bances, diarmea, weight gain, menorihagia, diminished sexua
dysfunction, ejaculatory dystunction, and orgastic dystunction.

The following adverse events occurred at an incidence of $1 \%$ or more, and were at least as frequent among RISPERDAL ${ }^{\circ}$ treated patients treated at doses of $\leq 10 \mathrm{mg} / \mathrm{day}$ than among placebo-treated patients in the pooled agitation, anxiety, somnolence, aggressive reaction. Nervous System: extraoyramidal symptoms', headache dizziness. Gastrolntestinal System: constipation, nausea dyspepsia, vomiting, aboominal pain, saliva increased, constipation, nausea, dyspepsia, vomiting, abdominal pain, saliva increased,
toothache. Respiratory System: thinitis coughing, sinusitis, pharyngitis, dyspnea. Body as a Whole: back pain chest pain, , sinusitis, pharygits, dyspnea. Body as a Whole: back pain, chest pain, tever. Dermatological; vision. Muscula-Skeletal: arthralgia. Cardiovascular: tachycardia

Includes tremor, dystonia, hypokinesia, hypertonia, hyperkinesia, oculogyric crisis, ataxia, abnormal gait, involuntary muscle contractions, hyporeflexia, Dose Dependency of Adverse Events:

Data from two fixed dose trials provided evidence of dose-relatedness for extrapyramidal symptoms associated with risperidone traatment. These symptoms include: sleepiness, increased duration of sleep, accommodation
disturbances, orthostatic dizziness, palpitations, weight gain, erectle dystunction, disturbances, orthostatic dizziness, palpitations, weight gain, erectile dystunction, ejaculatory dysfunction, orgastic dysfunction

Vital Sign Changes: RISPERDAL is associated with orthostatic hypotension and tachycardia (See PRECAUTIONS)

Weight Changes: A statistically significantly greater incidence of weight gain for AISPERDAL $(18 \%)$ compared to placebo $(9 \%)$.

Laboratory Changes: A between group comparison for 6- to 8-week placebocontrolled trials revealed no statistically significant RISPERDAL/placebo
differences in the proportions of patients experiencing potentially important

Shanges in routine serum chemistry, hematology, or urinalysis parameters. discontinutions for changes in serum chemistry, hematology or urincessis. discontinuations for changes in serum chemistry, hematology, or urnalysis.
However, RISPERDAL administration was associated with increases in serum prolactin (See PRECAUTIONS).

ECG Changes: The electrocardiograms of approximately 380 patients who received RISPERDAL and 120 patients who received placebo in two doubleblind, placebo-controlled trials were evaluated and revealed one finding of polentlal concern; i.e., 8 patients taking RISPERDAL Whose baseline QTC interval was less than $450 \mathrm{msec}$ were observed to have OTc intervals greater were not seen among about 120 placebo patients, but were seen in patients receiving haloperidol (3/126).

Other Events Observed During the Pre-Marketing Evaluatlon of RISPERDAL

During its premarketing assessment, multiple doses of RISPERDAL (risperidone) were administered to 2607 patients in phase 2 and 3 studies and the following reactions were reportad: (Note: frequent adverse events are those occurring in at least $1 / 100$ patients. Infrequent adverse events are those occurring in 1/100 to 1/1000 patients; rare events are those occurring in fower than $1 / 1000$ patients. It is important to emphasize that, although the events reported occurred during treatment with RISPERDAL", they were not necessarily caused by it.)

Psychiatric Disorders: Frequent: increased dream activity", diminished sexual catatonic reaction euphoria increased libido, amnesia. Rare: emotional lability, nightmares, delirium, withdrawal syndrome, yawning.

Central and Peripheral Nervous System Dlsorders: Frequent: increased sleep duration *. Intrequent: dysarthria, vertigo, stupor, paraesthesia, confusion. Rare: aphasia, choinergic syndrome, hypoesthesia, tongue paralysis, leg Gastro-intestinal DIsorders: Frequent: anorexia, reduced salivation*. Infrequent: flatulence, diarrhea, increased appetite, stomatitis, melena,
dysphagia, hemornhoids, gastritis. Rare: fecal incontinence, enuctation, gastrodysphagia, hemonhoids, gastritis. Rare: fecal incontinence, enuctation, gastrocholelithiasis, tongue edema, diverticulitis, gingivitis, discolored teces, Gi

Body as a Whole/General Disorders: Frequent: tatigue. Infrequent: edema, rigors, malaise, influenza-like symptoms. Rare: pallor, enlarged abdomen, allergic reaction, ascites, sarcoidosis, flushing.

Respiratory System Disorders: Infrequent hyperventilation, bronchospasm, pneumonia, stridor. Rare: asthma, increased sputum, aspiration.

Skin and Appendage Disorders: Frequent: increased pigmentation*, photosensitivity*. Infrequent: increased sweating, acne, decreased sweating, alopecia, hyperkeratosis, prunitus, skin exfoliation. Rare: bullous eruption, skin
ulceration, aggravated psoriasis, furunculosis, verruca, dermatitis lichenoid, ulceration, aggravated psoriasis, furuncul

Cardlovascular Disorders: Intrequent: palpitation, hypertension, hypotension, AV block, myocardial infarction. Rare: ventricular tachycardia, angina pectoris, premature atrial contractions, T wave inversions, venticular extrasystoles, ST depression, myocarditis.

Vision Dlsorders: Infrequent: abnormal accommodation, xerophthaimia Rare: diplopia, oye pain, blepharitis, photopsia, photophobla, abnormal

Metabollc and Nutritional Disorders: Infrequent: hyponatremia, weight increase, creatine phosphokinase increase, thirst, weight decrease, diabetes hypoproteinemia, hyperphosphatemia, hypertriglyceridemia, hyperuricemia, hypoglycemia.

Urinary System Disorders: Frequent: polyuria/polydipsia*. Infrequent urinary incontiner

Musculo-skeletal System Disorders: Infrequent: myalgia. Rare: arthrosis, synostosis, bursitis, arthritis, skeletal pain.

Reproductive Disorders, Female: Frequent: menorhagia*, orgastic dysfunction*, dry vagina*, Infrequent: nonpuerperal lactation, amenortiea, female breast pain, leukornhea, mastitis, dysmenorh
menstrual bleeding, vaginal hemorthage.

Liver and Blilary System Disonders: Infroquent: increased SGOT, increased SGPT. Rare: hepatic failure, cholestatic hepatitis, cholecystitis, cholelithiasis, hepattis, hepatocellular damage.

Platelet, Bleeding and Clotting Disorders: Infrequent: epistaxis, purpura. Rare: hemorthage, superficial phlebitis, thrombophlebitis, thrombocytopenia. Hearing and Vestibular Disorders: Rare: tinnitus, hyperacusis, decreased hearing

Red Blood Cell Dlsorders: Infrequent: anemia, hypochromic anemia. Rare: normocytic anemia.

Reproductive Disorders, Male: Frequent: erectile dystunction". Infrequent. ejaculation failure.

White Cell and Resistance Discride

Endocrine Olsorders: Rare: gynecomastia, male treast pain, artidiuretic

Special Senses: Rare: bitter taste.

"Incidence based on elicited reports.

Postintroduction Reports: Adverse events reported since market introduction which were temporally (but not necessarily causally) related to edema, apnea atrial fibrillation the tollowing: anaphylactic reaction, angioaggravated, including diabotic ketoacidosis, intestinal obstruction, jaundice, mania, pancreatitis, Parkinson's disease aggravated, pulmonary embolism. There have been rare reports of sudden death and/or cardiopulmonary arrest in patients receiving FISPERDAL . A causal relationship with RISPERDAL has not been established. It is important to note that sudden and unexpected whether they are treated with other antipsychotic drugs.

DRUG ABUSE AND DEPENDENCE

Controlled Substance Class: RISPERDAL (risperidone) is not a controlled substance.

For information on symploms and treatment of overdosage, see full prescribing informatton.

More detalied professional information is available upon request.

C. Janssen Pharmaceutica Inc. 1999

US Patent 4,804,663

7503217

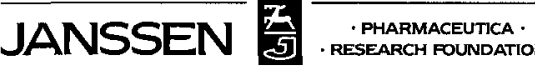

Titusville, NJ 08560 